\title{
SWELLING BEHAVIOR OF POLY (AAM_MA) HYDROGEL MATRIX AND STUDY EFFECTS PH AND IONIC STRENGTH, ENFORCEMENT IN CONTROLLED RELEASE SYSTEM
}

\author{
FAIQ F. KARAM ${ }^{\mathrm{a}^{*}}$, ASAWER A. MHAMMED ALZAYD
}

aDepartment of Chemistry, College of Science, University of Al-Qadisiyah, Iraq, bollege of Veterinary Medicine, University of Kerbala Email: faiq.karam@yahoo.com

Received: 24 Jul 2018, Revised and Accepted: 29 Oct 2018

\section{ABSTRACT}

Objective: The objective of this study was to estimate the performance of Acrylamide-malice acid (AAM_MA) hydrogel preparatory by free radical polymerization to loading/release Atenolol and Ciprofloxacin drugs from aqueous solution to be used in a controlled release system.

Methods: Free radical polymerization method has been used to prepare (AAM-MA) hydrogel. The prepared hydrogel was characterized by Fourier transform infrared (FTIR), Thermal Gravimetric Analysis/Derivative Thermal Gravimetric (TGA/DTG) and Field Emission Scanning Electron Microscopy (FE-SEM) techniques. The pH-dependent swelling behavior was investigated in addition to the effective ionic strength on adsorption and release system of the drug in vitro.

Results: Results showed that the highest swelling ration in $\mathrm{pH}=7.4$ and the same value of pH for the release of the drug. Thermal analysis test for prepared hydrogel showed good thermal stability. The hydrogel showed a negative effect with an increase saline contact Calcium carbonate appeared to have highly effect on releasing drugs from the polymeric network.

Conclusion: Higher ability of poly (AAM-MA) hydrogel to act as a carrier for the Ciprofloxacin and Atenolol with highest swelling and releasing under following conditions: at pH 7.4, at temperature $37{ }^{\circ} \mathrm{C}$ and the effect of ionic strength (charge/ratio) which indicate that the smaller radius have less effect on release and the largest charge have negative effect on release ratio that attributed to cation formation inter and intra complex surface hydrogel.

Keywords: Ciprofloxacin, Atenolol, Swelling ratio, Drug carriers, Polymeric network, Controlled release system, Biological half-life

(C) 2018 The Authors. Published by Innovare Academic Sciences Pvt Ltd. This is an open-access article under the CC BY license (http://creativecommons.org/licenses/by/4.0/) DOI: http://dx.doi.org/10.22159/ijap.2018v10i6.28724

\section{INTRODUCTION}

Over the past century, new chemical families have been discovered and produced, particularly in the broad domain of polymers life. In fact, polymers are defined as large molecules consisting of smaller repeated chemical units which are called monomers that become macromolecular polymers [1]. Polymers have various applications in medical, industrial, agricultural fields $[2,3]$. While they can use as a kind of adsorption and purification materials, the polymers are used as drugs carrier to improve pharmaceutical efficiency, pharmacodynamics and pharmacokinetic characteristics [4]. This usage is reflected in their role in reducing the side effects of the drugs that improve the bioavailability of the drug, prolong the biological halflife of drug and maintain the therapeutic efficiency which easily transfers hydrophobic drugs and improvement uptake by target body tissue $[5,6]$. The development carrier's drugs also improve the dissolution properties of poorly water-soluble drugs [7]. Hydrogel crosslinked polymer has a 3D network. Due to the fact that hydrophilic group is found in chemical structures such as $\mathrm{COOH}, \mathrm{NH}, \mathrm{OH}, \mathrm{SO}_{3} \mathrm{H}$ and $\mathrm{CONH}$, hydrogel has a capability to retain a quantity of water and biological field so that it suffers swelling $[8,9]$. Swelling behavior responds to the surrounding environment stimuli such as acidic function, temperature, ionic forces solvent composition, light, or electric field and magnetic field that either accept or release protons in response to changes in environmental $\mathrm{pH}$ so exploited swelling behavior to loading and release the drug in the body $[11,10]$. Atenolol is one of type beta blocker used mainly to treat hypertension, mycrocaial in functions and cardiovascular disease(CVD) [12]. Several studies have shown that this drug has a low absorption in colon and intestine, so the body can get rid of it quickly, therefore, it has a short half-life, a lack of bioavailability and dumping in the concentration of doses in plasma blood level because of the undesirable effects that include the central nerves system (CNS) [13]. The previous study proved that this drug may stay in sewage at $166 \mathrm{~d}$ to these [14], reasons requires to develop a method that takes this drug to prolong the period in the body and achieves the highest therapeutic effectiveness. On the other hand, wastewater is treated from its pharmaceuticals compound [15]. The antibiotic also suffers a low absorption in the human body and a short half-life like ciprofloxacin. One of its kinds is fluoroquinolone group that is frequently used from both human and animals. Due to its inexpensiveness and its availability, it is used to treat gram-negative bacterial infections, respiratory, abdominal infections bacterial diarrheal infections urinary tract infections, skin, ophthalmic and respiratory infection [16, 17]. Controlled release systems show many good features over traditional dosage forms. In addition to tamper the rate of release, drug packaging provides, among other things, protection from a medical decomposition, chemical degradation and low drug toxicity [18]. Hence, the study was aimed to estimate the performance of (acrylamide-maleic acid) hydrogel preparatory by free radical polymerization to loading/release both Atenolol and ciprofloxacin drugs from aqueous solution to used in controlled release system.

\section{MATERIALS AND METHODS}

\section{Materials}

Acrylamide and maleic acid were supplied by (Himedia, India). The activator $\mathrm{N}, \mathrm{N}, \mathrm{N}^{\prime}, \mathrm{N}^{\prime}$-tetramethylethylenediamine (TMEDA) supplied from Merck(Darmstadt, Germany) were used as the redox initiator pair, the initiator potassium persulfate (KPS) was supplied by(Merck, Germany). The multifunctional crosslinker is $\mathrm{N}^{\mathrm{N}} \mathrm{N}^{\prime}-$ methylene bis-a crylamide (NMBA) was purchased from (Fluka, Germany). Sodium chloride, Carbonate Calcium, and Potassium chloride were obtained from (Fluka, Germany). Atenolol (ATL) was purchased from (Basic Pharma Life Science Pvt. Ltd, India). Ciprofloxacin (CIP) was purchased from (Basic Pharma Life Science Pvt. Ltd, India). Sodium Hydroxide and Hydrochloric acid were supplied from (Fluka, Germany).

Chemical preparation of cross-linked poly (AAM-co-MA) Hydrogels

The hydrogel was prepared according to the method of (Y. Murali Mohan) et al., they used a free radical polymerization as shown in fig. 1 which demonstrates the steps of polymer preparation with the suggested structural form [19]. 


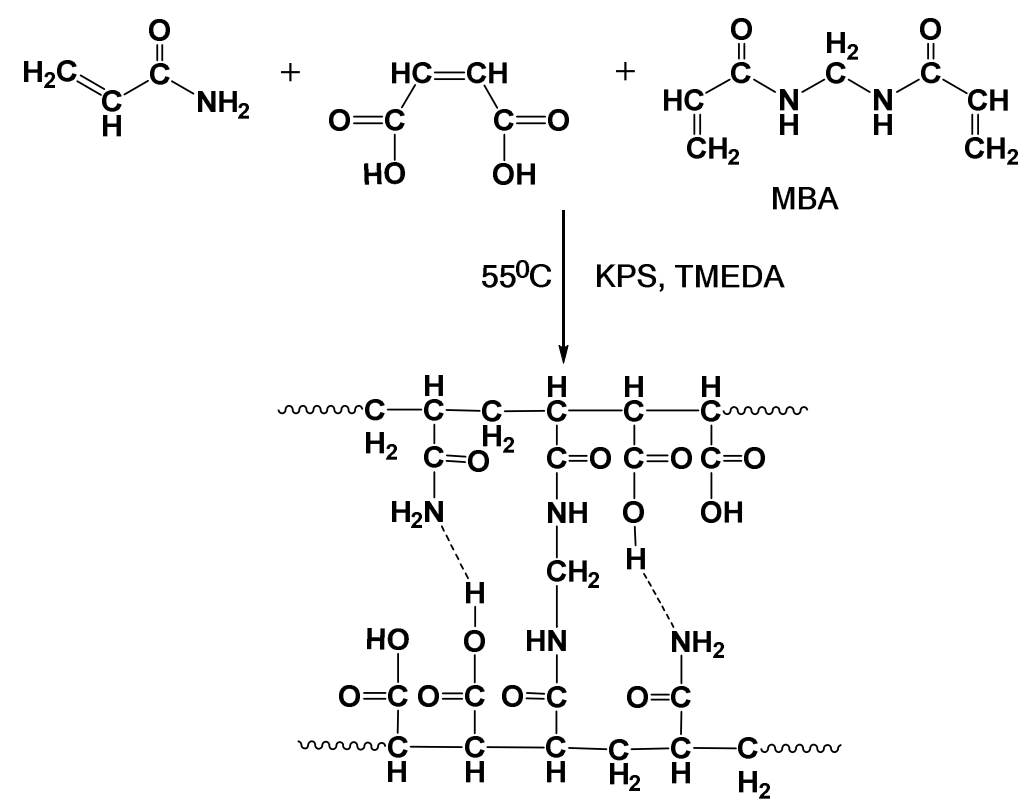

Fig. 1: Preparation steps of hydrogel

\section{Drug loading and preparation of matrix tablet}

Loading of drug on hydrogel by swelling equilibrium so left $(1 \mathrm{~g})$ from hydrogel in highly concentration $\mathrm{pH}=4$ and 6 of drugs aqueous solution to ciprofloxacin and atenolol respectively then left at $24 \mathrm{~h}$ at room temperature to late the drug being saturated with polymeric network then it used a thermostatically controlled incubator with shaking speed of $150 \mathrm{cycle} / \mathrm{min}$ at $15{ }^{\circ} \mathrm{C}$,then dried at $45^{\circ} \mathrm{C}$, follow grained to made matrix tablet by pharmaceutical compress device(TP1.5, china) to be ready for usage and studding release of drug in vitro to calculate lauded drug amount according to the equation 1.

$$
Q_{6=} C_{0} C_{e} m \text { mivi }
$$

$\mathrm{V}_{\text {sol }}$ : solution volume in $\mathrm{l}$

$\mathrm{C}_{\mathrm{o}}$ : $\mathrm{C}_{\mathrm{e}}$ : initial concentration and concentration at equilibrium in $\mathrm{mg} / \mathrm{l}$

$\mathrm{m}$ : weight of the polymer in $\mathrm{g}$

Qe: quantity of drug in $\mathrm{mg} / \mathrm{g}$ [20]

\section{Drug release studies}

Hydrogel matrix tablet to both drugs was put in different $\mathrm{pH}$ solution $(1.2,5,7.4$ and 11) which is similar to the temperatures of stomach, colon and intestines environments. Shaking in a thermostatically controlled at $37{ }^{\circ} \mathrm{C}$ with speed of $150 \mathrm{cycle} / \mathrm{min}$, then centrifuged at $6000 \mathrm{rpm}$ (D-78532 Tuttlingen $6000 \mathrm{U} / \mathrm{min}$ Hettich Triup, Germany) for $10 \mathrm{~min}$. The amount of released drug was calculated by ultraviolet-visible (spectrophotometer) at 275.5 $\mathrm{nm}$ and apply equation 2 .

$$
\text { Amount drug release }=\frac{C_{e^{* V}}}{m} \text {. }
$$

$\mathrm{C}_{\mathrm{e}}$ : Concentration of the released drug at equilibrium in $\mathrm{mg} / \mathrm{l}$

$\mathrm{V}$ : Volume of solution in 1

m: adsorbent weight in g. [21]

\section{Swelling study}

Determination of the highest swelling percentage of hydrogel was needed to be applied in different $\mathrm{pH}$. Several $\mathrm{pH}$ media were prepared (1.2, 5, 7.4 and 11), $1 \mathrm{mg}$ from dry hydrogel was taken and soaked then lifted swelling after that removal of an aqueous solution at regular intervals and dried with associate filter paper to gate for accurate weight. The swelling ratio is calculated by equation 3 .

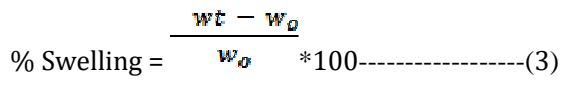

Wt: Weight after swelling

$\mathrm{W}_{\mathrm{o}}$ : Weight before swelling [22]

\section{Characterization of hydrogel}

\section{FT. IR measurement}

The drugs were identified by FTIR (Shimadzu, Japan, 8500) used Potassium bromide $(\mathrm{KBr})$ disk technique. The spectra were recorded from $(4000-400) \mathrm{cm}^{-1}$.

\section{Morphology}

The morphology of surface for both hydrogel and hydrogel matrix was observed by Field Emission Scanning Electron Microscopy (FESEM) (JEOL, JSM-6701F, Japan) the samples observed under nitrogen gas vacuum and accelerated potential $8.0 \mathrm{kv}$.

\section{Thermal test}

This test was studied by using TG/DTG (Perkin Elmer,USA,TGA4000) to estimate the physical properties by taking $10 \mathrm{mg}$ of sample with a heating rate $10{ }^{\circ} \mathrm{C} / \mathrm{min}$ and heating range from $(40-800)^{\circ} \mathrm{C}$ in the presences of nitrogen gas.

\section{RESULTS AND DISCUSSION}

\section{The swelling}

Swelling behavior of hydrogel that increases or decreases is affected by several factors. One of the most important factors is the change of $\mathrm{pH}$ cause ionization or protonation of a functional group on hydrogellike carboxyl group ionized in basic medium to become a carrier of the negative charge then increasing of volume hydrogel. In the studied hydrogel, the result reveals a high swelling ratio in $\mathrm{pH}=7.4$ to presence two carboxyl group carried a negative charge in hydrogel that has lead to a repulsion between negative charge that belongs to (CON-)and also a repulsion between(-COO--)and a baring electron on nitrogen in amide group [23]. When comparing swelling ratio with the same polymer, which prepared by ( $\mathrm{\gamma}$-ray) radiation that prepared by the researcher (Eid), we can observe that the polymer in our studies has higher swelling, it reached to 1500 after $30 \mathrm{~h}$ while other polymer reached to 800 after $120 \mathrm{~h}$ [24]. This increase in swelling ratio results from an increase in the number of carboxylic groups carrying the negative charge repulsion. Fig. 2, shows swelling ratio to (AAM-co-MA) hydrogel in different $\mathrm{pH}$ values. 


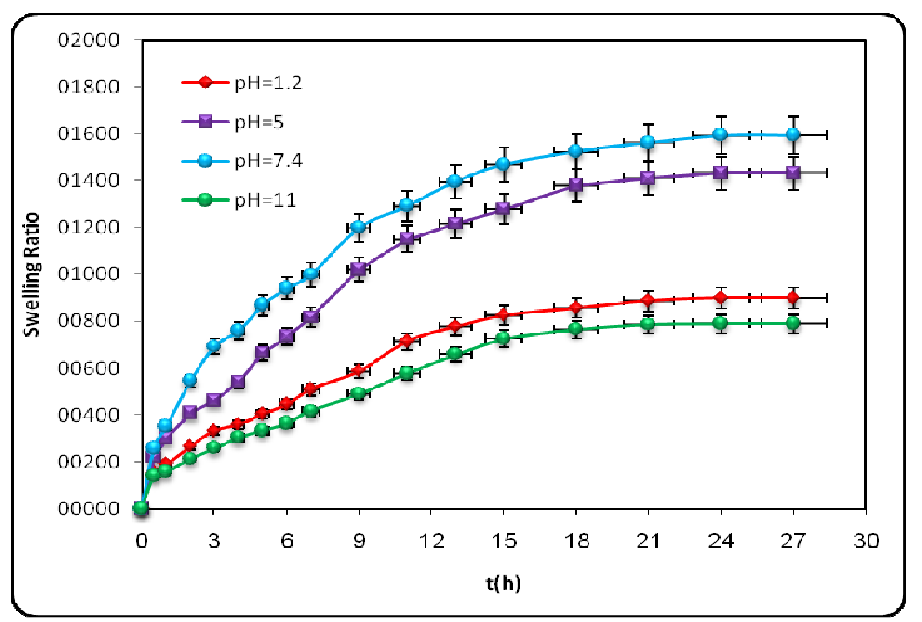

Fig. 2: Swelling behavior of the $1 \mathrm{~g}$ of the hydrogel at different $\mathrm{pH}$ values, all the values were calculated as mean \pm standard deviation; $\mathrm{n}=3$

\section{Fourier transform infrared spectroscopy (FT-IR)}

Fig. 3 represents FTIR spectra before loading drug, the chemical structure is confirmed by FTIR and can have a follow-up change on functional group and shifted in wave number to both compound hydrogel matrix, we noticed large differences peaks between hydrogel and hydrogel matrix that belong to both drugs. The differences indicate the interface between drug and adsorbent surface (hydrogel). Spectra appeared before the loaded broadband is $3500-3200 \mathrm{~cm}^{-1}$ to nip up stretching vibration amid and a hydroxyl group. Other bands in the $(2830$ and 2717$) \mathrm{cm}^{-1}$ to asymmetrical and symmetrical stretching of a methylene group. Also, other important band showed a sharp in 1659,1613 that belongs to $\mathrm{C}=0$ stretching vibration to both carboxylic and Amide group respectively [25]. The chart for both drug shows a shift in the wave number in the peak that belongs to $\mathrm{C}=0$ in the region of 3500-3100 due to the occurrence of hydrogen bounding between drugs and hydrogel surface. New bands appeared in drugs charts belong to appeared anew peaks retune aromatic group at presence in structured drugs like $(\mathrm{C}=\mathrm{C})$ searching in $1500 \mathrm{~cm}^{-1}$ and bending out of plane $940 \mathrm{~cm}^{-1}$ in ciprofloxacin drugs also appear (C-F)stretching in $670 \mathrm{~cm}^{-1}$ belong to ciprofloxacin drug in fig. 4 and fig. 5 we can observe the difference between two drugs $[26,27]$.

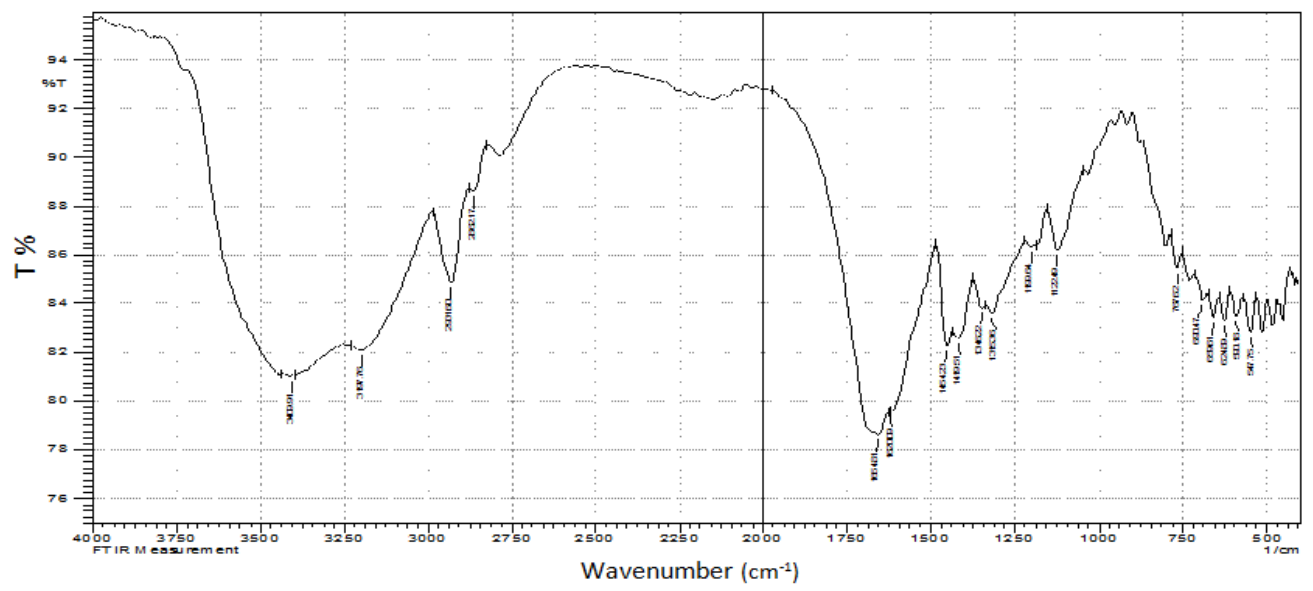

Fig. 3: FTIR spectra of hydrogel

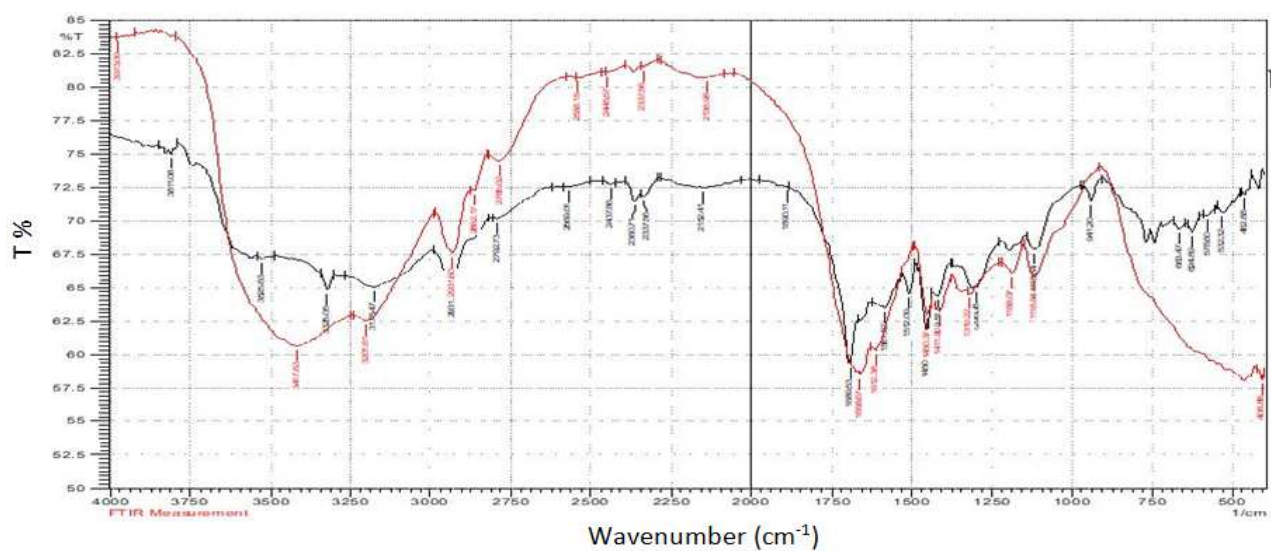

Fig. 4: FTIR spectra of atenolol loaded on hydrogel 


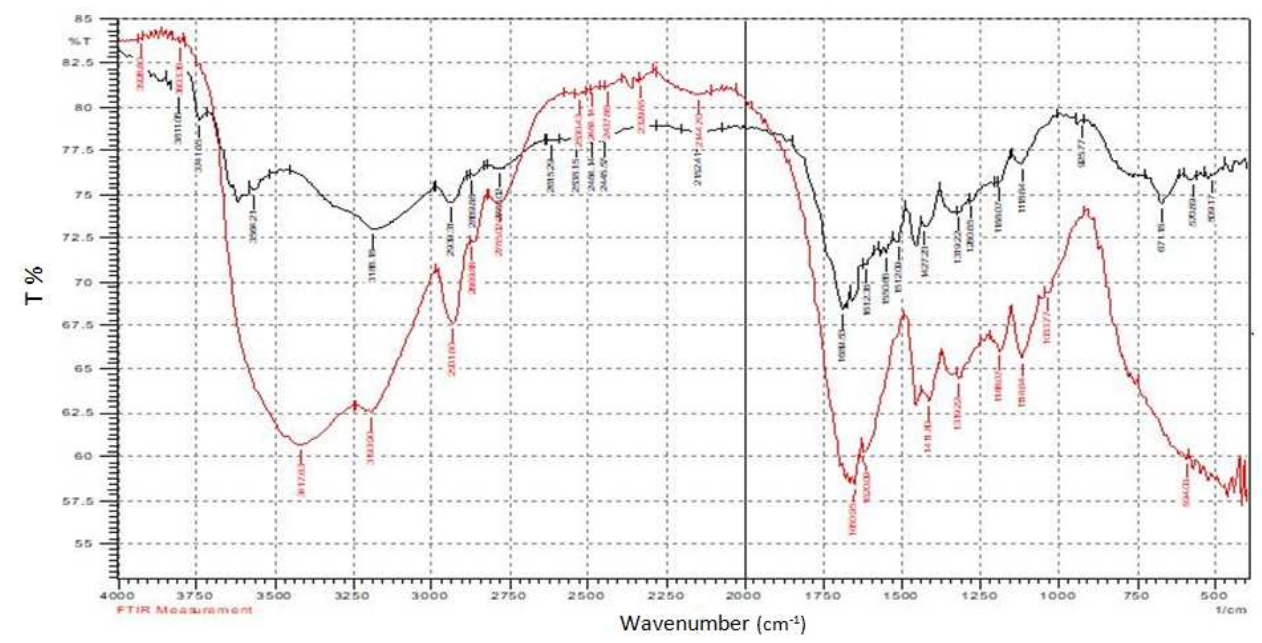

Fig. 5: Spectrum of ciprofloxacin loaded on hydrogel

\section{Field emission scanning electron microscopy (FESEM) imaging}

Field emission-scanning electron microscopy (FESEM) is an important magnification tool for examining the surface topography as before and after loaded pharmaceutical compounds. FESEM pictures were taken at magnification value $200 \mathrm{~nm}$ for each surface by hydrogel and matrix tablet to both drugs in fig. 6(A). It was observed the surface hydrogel that was seen homogenous granular and founded slit between granular, fig. 6(C), clarify atenolol drug loaded on hydrogel and seem heterogeneous form but in fig. 6(B)which represents ciprofloxacin drug loaded on hydrogel it has seen homogenous granular and looks as waves. FESEM is better than the SEM because FESEM higher resolution and the lower ratio(S/N), so it is fit to be a sensitive sample like drugs [28, 29].
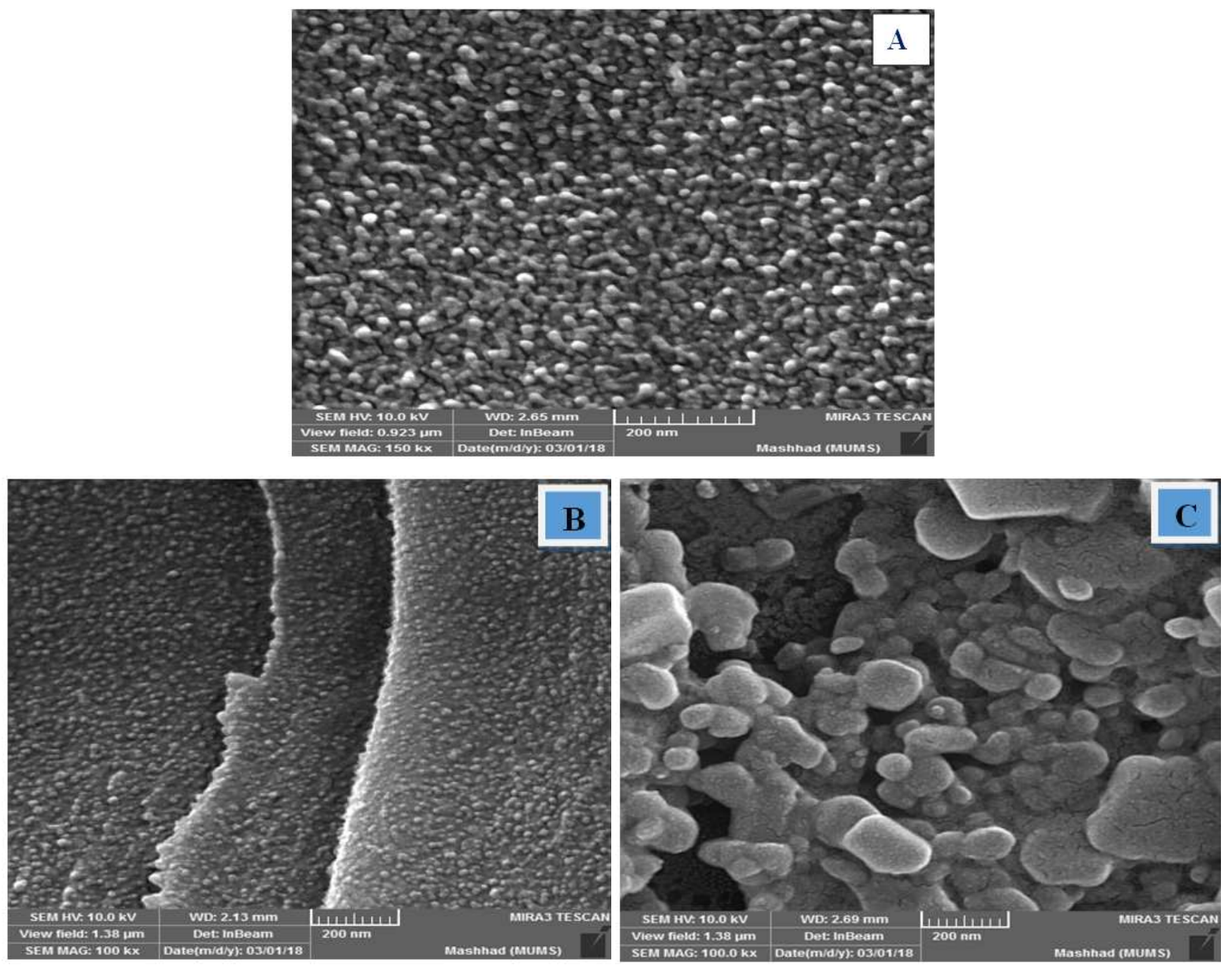

Fig. 6: FE-SEM image of surface hydrogel in $200 \mathrm{~nm}$ and magnification150kx, B and C-FE-SEM image of ciprofloxacin and Atenolol magnification $100 \mathrm{kx}$ respectively 


\section{Thermal analysis}

Fig. 7,showed the integration of TG/DTG curves in this fig., continuous line represents thermal gravimetric analysis while the dashed line represents derivational thermal analysis. The DTG curve has less interference from the TG curve and the peaks reflect the chemical reaction occurring during an increase in temperature within the time unit. [30]. TG curve shows a three stages of losses of weight, initial stage in $117{ }^{\circ} \mathrm{C}$ attribute to loss moisture (humidity) that found in the hydrogel, second stage when reached temperature between range (257$332){ }^{\circ} \mathrm{C}$ belong to loss $\mathrm{CO}_{2}$ and amide group and respective this is identical to what observed researcher Yaoji Tang et, al., they studied removal pigment by AA-MA.[31]. Third stage represents the dissociation of polymer in $383.84{ }^{\circ} \mathrm{C}$ to refer degradation of the polymer backbone. The DTG clarify loss $\% 12,02$ of weight in $1,34 \% \mathrm{~min}$, the second stage represents loss of 75,4\% belong to loss two group of $\mathrm{CO}_{2}$ and amide and the last stage loss $58.0 \%$ in 13.6 min due to degradation of the polymer chain so (TG/DTG) appear good thermal stability to prepared hydrogel.

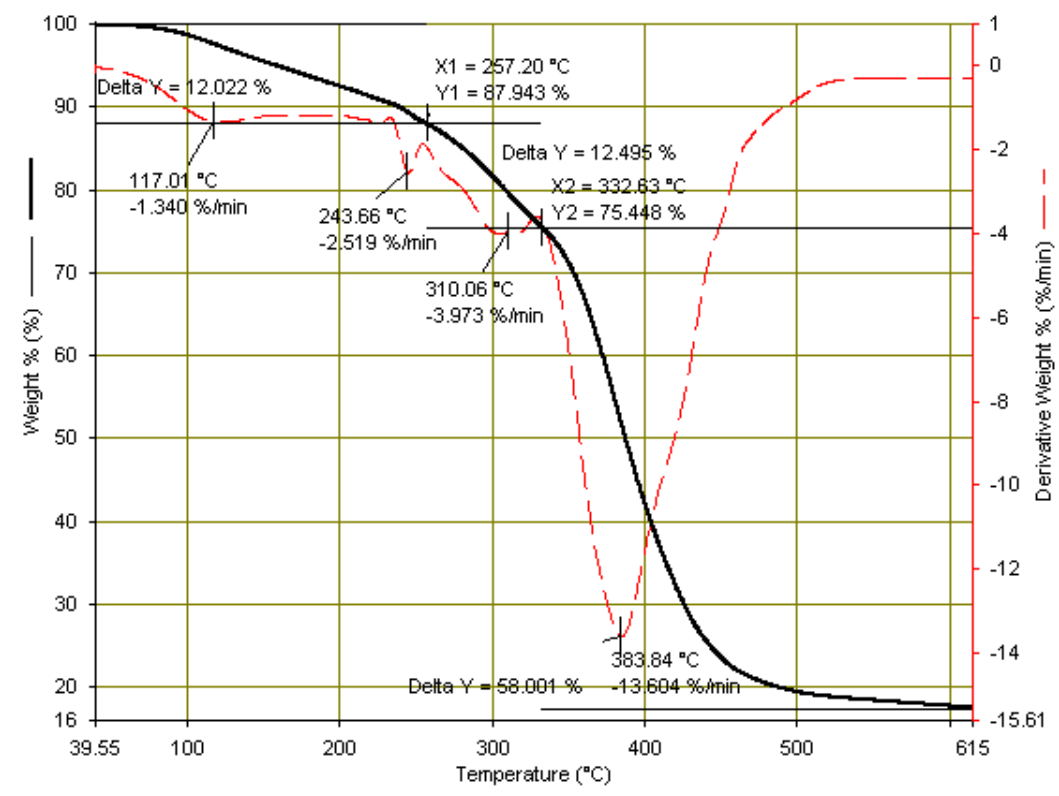

Fig. 7: TG/DTG curve for hydrogel AAM-co-MA

\section{Effect of $\mathrm{pH}$ on the release of drug in vitro}

The release of drugs was studied in different $\mathrm{pH}$ media (1.2, 5 and 7.4) represented small intestinal, colon, stomach respectively. The study showed the highest release values to both drugs in $\mathrm{pH}=7.4$, we can interpret the protonation and ionization carboxyl group in surface hydrogel [32] as having abundant, this group in ( $\mathrm{pH}=1.2)$ was protonation so that it forms $(\mathrm{COOH})$ which means that the electrostatic repulsion is not found and has not led to swelling, in addition, hydrogen bond was found to restrict the swelling by hydrogel. In either the virtual bowel fluid the carboxyl group were ionization to have a negative charge ( $\mathrm{COO}^{-}$), the negative charge helps to form the electrostatic repulsion between similar charge so that swelling is obtained. it has the largest drug matrix tablet and separated the hydrogen bonding and spread out drug outside polymeric network in $\mathrm{pH}=5$ not ionization most of carboxyl group so the swelling behavior is not the greatest [33], as well the ratio of release ciprofloxacin is higher than from atenolol that due to drug solubility, because the solubility of atenolol reached $13 \mathrm{~g} / \mathrm{l}$ while ciprofloxacin $30 \mathrm{~g} / \mathrm{l}$ when raised solubility of drug reduced adsorption and increase release ratio from polymeric network due to easy leave it [34]. The results of ciprofloxacin and atenolol are shown in fig. 9 and fig. 10.

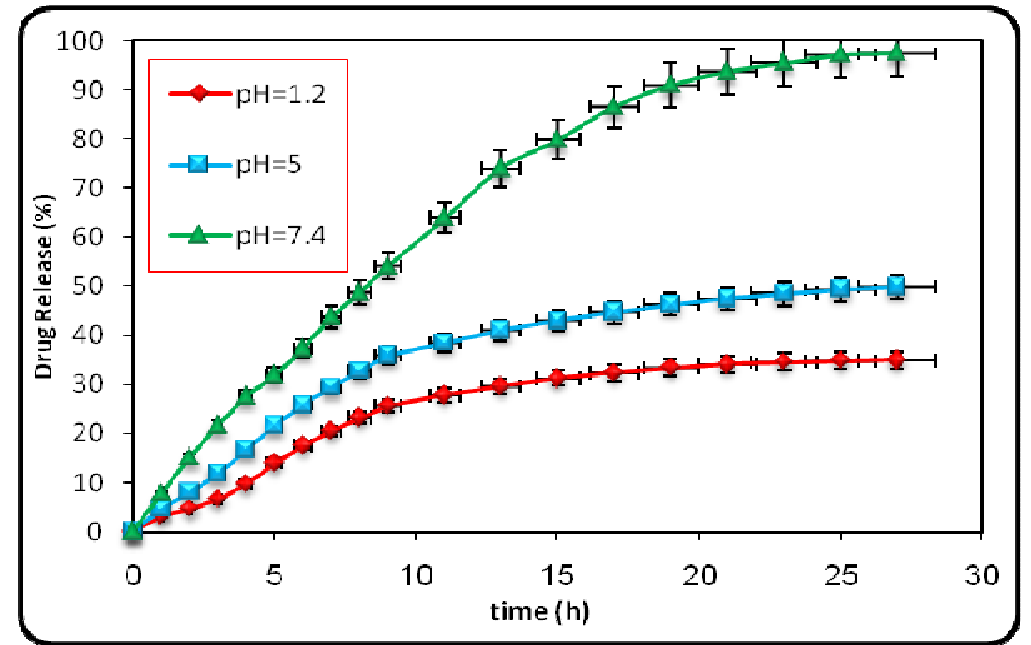

Fig. 8: Effect of acid function on the amount of ciprofloxacin released from the tablets at $37^{\circ} \mathrm{C}$, all the values were calculated as mean \pm standard deviation; $n=3$ 


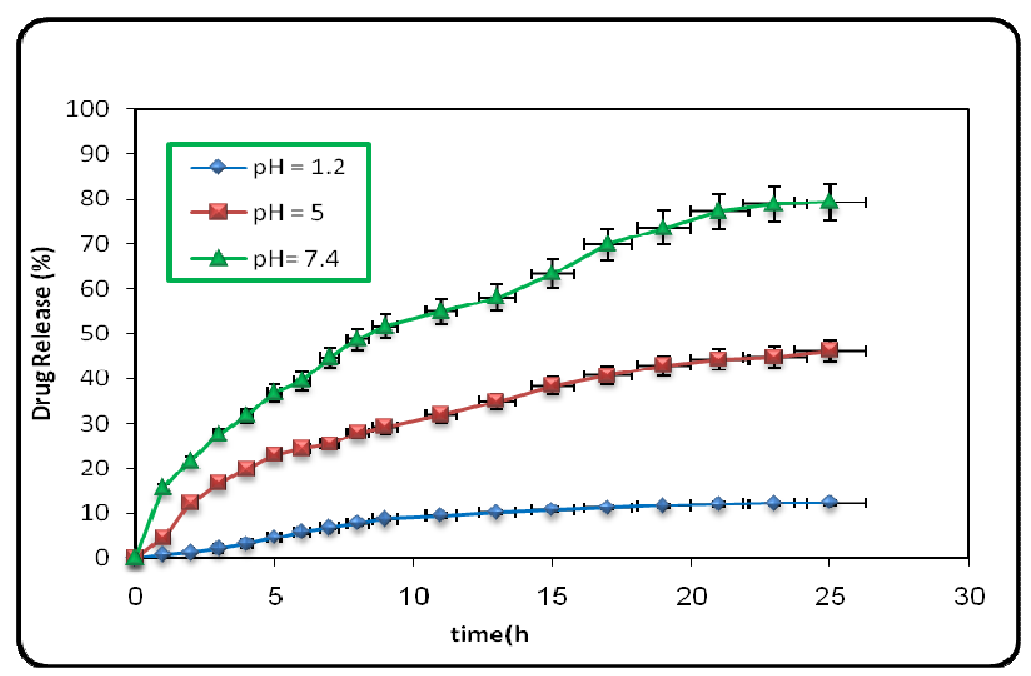

Fig. 9: Effect of acid function on the amount of atenolol released from the tablets at $37^{\circ} \mathrm{C}$, all the values were calculated as mean \pm standard deviation; $\mathbf{n}=\mathbf{3}$

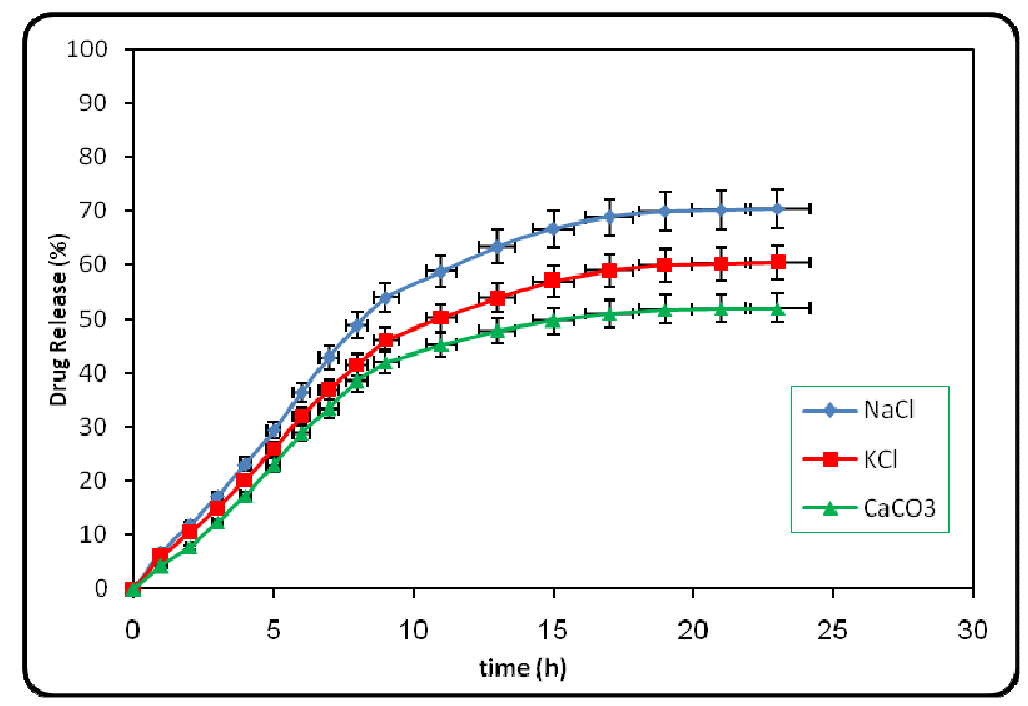

Fig. 10: Effect of ionic strength on ciprofloxacin drug that released from the matrix tablet at $37^{\circ} \mathrm{C}$ and $\mathrm{pH}$ 7.4, All the values were calculated as mean \pm standard deviation; $n=3$

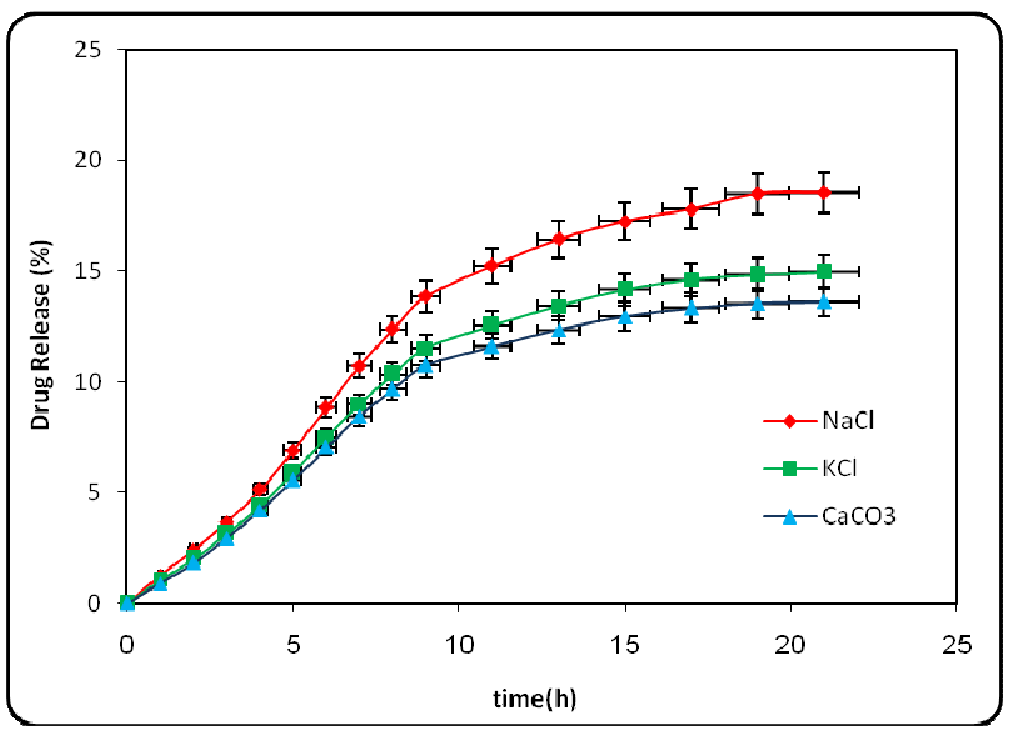

Fig. 11: Effect of ionic strength on atenolol drug that released from the matrix tablet at $37^{\circ} \mathrm{C}$ and $\mathrm{pH} 7.4$, all the values were calculated as mean \pm standard deviation; $n=3$ 


\section{Effect of ionic strength on the release of drug in vitro}

Through examining the effect ionic strength, we got the following result in fig. 10 for ciprofloxacin and fig. 11 for atenolol. We observed a negative effect on release drugs from matrix tablet. The mechanism of this behavior can be understood as following: due to the continuous ability to penetrate the polymer network and correlation with carboxylic groups (COO-) to the surface polymer that is operating too feeble(anion-anion)electrostatic interaction, we can observed an increase in the ionic value of the used salt that has led to decrease the release ratio because of an increase in the ability to form intermolecular complex on surface hydrogel that has led to reinforcing cross-linked on surface which is resulted in ability to imbibitions water and biological fluids to the polymeric Network so it shrinks as a result of shielding from complex. The smaller diameter of cation made less effect on swelling polymer so we can arrangement based effect on swelling ratio $\left(\mathrm{Na}^{+1}<\mathrm{K}^{+1}<\mathrm{Ca}^{+2}\right)$, that agree with researcher Che et, al., when evaluated performance chitosan-based hydrogels for controlled drug delivery [35] on the other hand, the decrease in adsorption capacity may be due to osmotic pressure between external incubation and inner hydrogel fortified with raise ionic strength. The water content within the hydrogel network will then spread and shrink. This indicates that increasing salt concentration will accelerate the release of water molecules from the network polymer then reduced of swelling ratio that agree with study Xiaoliang et al. [36].

\section{CONCLUSION}

Results revealed the ability to use poly (AAM-MA) hydrogel as a carrier of the drugs in the intestinal tract, which attributed to the hydrogel that had a higher swelling behavior ratio in hypothetical intestinal. The results also showed a solubility effect on releasing ratio from the polymeric network. The results displayed the effect of ionic strength (charge/radius) to cation on release ratio of release drugs. The smaller radius had less effect on release, and the largest charge had a negative effect on release ratio that was due to cation formation inter and intra complex surface hydrogel.

\section{ACKNOWLEDGMENT}

Authors are thankful to the University of Al-Qadisiyah for their technical support.

\section{AUTHORS CONTRIBUTIONS}

All the author have contributed equally

\section{CONFLICT OF INTERESTS}

Declared none

\section{REFERENCES}

1. Feldman D. Polymer history. Des Monomers Polym 2008;11:1-15.

2. Hamid AMS, Rehman K, Chen S. Natural and synthetic polymers as drug carriers for delivery of therapeutic proteins. Polym Rev 2015;55:371-406.

3. Kaur R, Kaur S. Role of polymers in drug delivery. J Drug Delivery Ther 2014;4:32-6.

4. Srivastava A, Yadav T, Sharma S, Nayak A, Kumari AA, Mishra N Polymers in drug delivery. J Br Med 2015;4:69.

5. Zhang Y, Sun T, Jiang C. Biomacromolecules as carriers in drug delivery and tissue engineering. Acta Pharm Sin B 2017;8:34-50.

6. Larraneta E, Stewart S, Ervine M, Al-Kasasbeh R, Donnelly RF. Hydrogels for hydrophobic drug delivery classification, synthesis and applications. J Funct Biomater 2018;9:1-20.

7. Sivapriya V, Ponnarmadha S, Abdul Azeezand N, Sudarshanadeepa V. Novel nanocarriers for ethnopharmacological formulations. Int J Appl Pharm 2018;10:26-30.

8. Caccavo D, Cascone S, Lamberti G, Barba AA. Hydrogels: experimental characterization and mathematical modeling of their mechanical and diffusive behavior. Chem Soc Rev 2018;47:2357-73.

9. Leon O, Munoz-Bonilla A, Soto D, Ramirez J, Marquez Y, Colina $\mathrm{M}$, et al. Preparation of oxidized and grafted chitosan superabsorbents for urea delivery. J Polym Environ 2018;26:728-39.
10. Yahia L, Chirani N, Gritsch L, Motta FL, Fare S. History and applications of hydrogels. J Biomedical Sci 2015;4:1-23.

11. Mohy Eldin MS, Omer AM, Wassel MA, Tamer TM, Abd Elmonem MS, Ibrahim SA. Novel smart pH sensitive chitosan grafted alginate hydrogel microcapsules for oral protein delivery: i. preparation and characterizationoriginal. Int J Pharm Pharm Sci 2015;7:320-6.

12. Lal S, Datta M. In vitro prolonged gastric residence and sustained release of atenolol using novel clay-polymer nanocomposite. Appl Clay Sci 2015;114:412-21.

13. Marques SC, Mestre AS, Machuqueiro M, Gotvajn AZ, Marinsek M, Carvalho AP. Apple tree branches derived activated carbons for the removal of $\beta$-blocker atenolol. Chem Eng J 2018;345:669-78.

14. Dehdashti B, Amin MM, Pourzamani H, Rafati L, Mokhtari M. Removal of atenolol from aqueous solutions by multiwalled carbon nanotubes modified with ozone: kinetic and equilibrium study. Wat Sci Tech 2018;3:1-14.

15. Ahmed MB, Zhou JL, Ngo HH, Guo W. Adsorptive removal of antibiotics from water and wastewater: progress and challenges. Sci Total Environ 2015;532:112-26.

16. Wang L, Chen G, Ling C, Zhang J, Szerlag K. Adsorption of ciprofloxacin on to bamboo charcoal: effects of $\mathrm{pH}$, salinity, cations, and phosphate. Environ Prog Sustain Energy 2017;36:1108-15.

17. Vidyavathi M, Srividya G. A review on ciprofloxacin. Int J Appl Pharm 2018;10:6-10.

18. Qi X, Wei W, Su T, Zhang J, Dong W. Fabrication of a new polysaccharide-based adsorbent for water purification. Carbohydr Polym 2018;195:368-77.

19. Murali Mohan Y, Sudhakar K, Keshava Murthy PS, Mohan Raju K. Swelling properties of chemically crosslinked poly (acrylamide-co-maleic acid) hydrogels. Int J Polym Mater 2006;55:513-36.

20. Ngeno EC, Orata F, Lilechi DB, Shikuku VO, Kimosop S. Adsorption of caffeine and ciprofloxacin onto pyrolytically derived water hyacinth biochar: isothermal, kinetic and thermodynamic studies. J Chem Chem Eng 2016;10:185-94.

21. Ali DJ, Al-Bayati RA, Alani RR. Adsorption-desorption and theoretical study of propranolol hydrochloride drug on chitosan and cellulose acetate surfaces. Br J Pharm Res 2016;10:1-8.

22. Abdel Bary EM, Harmal AN, Saeed A, Gouda MA. Design, synthesis, characterization, swelling and in vitro drug release behavior of composite hydrogel beads based on methotrexate and chitosan incorporating antipyrine moiety. Polym Plast Technol Eng 2018;57:1-9.

23. Kim B, Lim SH, Ryoo W. Preparation and characterization of $\mathrm{pH}$-sensitive anionic hydrogel microparticles for oral proteindelivery applications. J Biomater Sci Polym Ed 2009;20:427-36.

24. Eid M. Gamma radiation preparation of poly (Acrylamide/Maleic Acid/Gelatin) hydrogels for adsorption of chromium ions from wastewater. Asian J Pharm Sci Biotechnol 2015;1:9-14.

25. Abdel-Aziz HM, Hanafi HA, Abozahra SF, Siyam T. Preparation of poly (acrylamide-maleic Acid) resin by template polymerization and its use for adsorption of Co (II) and Ni (II). Int J Polym Mater 2010;60:89-101.

26. Rao DK, Damodharam T, Yadav JS, Suresh Babu P. Removal of atenolol ( $\beta$-blocker) from the aqueous phase by sorption onto activated charcoal. Int J Pharm Chem Sci 2013:2:26-32.

27. Jalil MER, Baschini M, Sapag K. Influence of $\mathrm{pH}$ and antibiotic solubility on the removal of ciprofloxacin from aqueous media using montmorillonite. Appl Clay Sci 2015;114:69-76.

28. Bazhan Z, Ghodsi FE, Mazloom J. The surface wettability and improved electrochemical performance of the nanostructured CoxFe3- xO4 thin film. Surf Coat Technol 2017;309:554-62.

29. Zheng Y, Cosgrove DJ, Ning G. High-resolution field emission scanning electron microscopy (FESEM) imaging of cellulose microfibril organization in plant primary cell walls. Microsc Microanal 2017;23:1048-54.

30. Ferriol M, Gentilhomme A, Cochez M, Oget N, Mieloszynski JL. Thermal degradation of poly (methyl methacrylate)(PMMA): modelling of DTG and TG curves. Polym Degrad Stab 2003;79:271-81. 
31. Tang Y, Wang X, Zhu L. Removal of methyl orange from aqueous solutions with poly (acrylic acid-co-acrylamide) superabsorbent resin. Polym Bull 2013;70:905-18.

32. Khan A, Othman MBH, Razak KA, Akil HM. Synthesis and physicochemical investigation of chitosan-PMAA-based dualresponsive hydrogels. J Polym Res 2013;20:273-82.

33. Bajpai SK, Johnson S. Poly (acrylamide-co-maleic acid) hydrogels for removal of $\mathrm{Cr}(\mathrm{VI})$ from aqueous solutions, part 1: synthesis and swelling characterization. J Appl Polym Sci 2006;100:2759-69.
34. Ramana Reddy KV, Nagabhushanam MV. Process and parameters are affecting drug release performance of prepared cross-linked alginate hydrogel beads for ezetimibe. Int J Pharm Pharm Sci 2017;9:254-62.

35. Che Y, Li D, Liu Y, Ma Q Tan Y, Yue Q, et al. Physically cross-linked pH-responsive chitosan-based hydrogels with an enhanced mechanical performance for controlled drug delivery. RSC Adv 2016;6:106035-45.

36. Qi X, Li J, Wei W, Zuo G, Su T, Pan X, et al. Cationic salecan-based hydrogels for release of 5-fluorouracil. RSC Adv 2017;7:14337-47. 